\title{
Prenatal diagnosis of rearrangements in the fetal 22q11.2 region
}

\author{
Suping Li ${ }^{* \dagger}$, Yuxia Jin ${ }^{\dagger}$, Jing Yang, Li Yang, Ping Tang, Chiyan Zhou, Liping Wu, Jinhua Dong, Jie Chen \\ and Huaxiang Shen
}

\begin{abstract}
Background: 22q11.2 deletion syndrome (22q11.2DS) and 22q11.2 duplication syndrome (22q11.2DupS) are the most common copy number variations in humans. The clinical phenotypes of these two syndromes are variable, and there are no large sample data on the prenatal detection rate for these two syndromes in the Chinese population.
\end{abstract}

Results: We recruited 411 pregnant women who showed either abnormal prenatal ultrasound findings or positive prenatal $\mathrm{BoBs}^{\mathrm{TM}}$ results or who had given birth to a child with chromosomal abnormalities. SNP-array analysis and interphase FISH analysis identified five fetuses with 22q11.2 copy number variants (CNVs), three of which were 22q11.2 deletion syndrome (22q11.2DS) (3/411) and two of which were 22q11.2 duplication syndrome (22q11.2DupS). In all 5 cases of diagnosed 22q11.2 abnormalities, inheritance could not be identified because the parents did not undergo further testing.

Conclusion: Our case reports provide a detection rate of 22q11.2 CNVs for fetuses with prenatal diagnostic indications, and early diagnosis of these two syndromes was essential for prenatal intervention in these cases. SNP-array technology is an effective tool in the prenatal diagnosis of 22q11.2 CNVs. The prenatal diagnosis of these two syndromes is helpful for early intervention, which is of great clinical significance.

Keywords: 22q11.2 deletion syndrome, 22q11.2 duplication syndrome, Prenatal diagnosis, Single-nucleotide polymorphism-array analysis, Chromosome analysis

\section{Background}

$22 \mathrm{q} 11.2$ deletion syndrome (22q11.2DS) is one of the most common and best-characterized recurrent chromosomal deletion syndromes [1], with an incidence of approximately 1 in 1000 fetuses [2] and 1 in 4000 live births [3]. Most chromosome 22 genomic abnormalities are due to low copy repeat sequence (LCR)-mediated nonhomologous dislocations and uneven intrachromosomal or interchromosomal recombination during meiosis. The 22q11.2 region is rich in LCRs, making this region a

\footnotetext{
*Correspondence: lilly2007@126.com

${ }^{\dagger}$ Suping Li and Yuxia Jin contributed equally to this work.

Department of Prenatal Diagnosis Center, Jiaxing University Affiliated Women and Children Hospital, East Zhong huan Road, 2468\#, Jiaxing 314050, Zhejiang, China
}

high incidence area of chromosome 22 abnormalities as a result of both intrachromosomal or interchromosomal nonallelic homologous recombination events [4]. Most patients with 22q11.2DS have congenital heart disease, immune deficiency, transient neonatal hypocalcemia, velopharyngeal insufficiency, a distinctive facial appearance, variable cognitive delays, behavioral anomalies, and psychiatric illness [1,2].

A duplication interchromosomal event in the same region of chromosomal 22q11.2 causes a syndrome referred to as $22 \mathrm{q} 11.2 \mathrm{DupS}[5,6]$. It is thought that the morbidity of 22q11.2DupS is half that of 22q11.2DS. This syndrome is characterized by a highly variable clinical phenotype, which ranges from apparently normal or slightly dysmorphic features with moderate learning

(c) The Author(s). 2020 Open Access This article is licensed under a Creative Commons Attribution 4.0 International License, which permits use, sharing, adaptation, distribution and reproduction in any medium or format, as long as you give appropriate credit to the original author(s) and the source, provide a link to the Creative Commons licence, and indicate if changes were made. The images or other third party material in this article are included in the article's Creative Commons licence, unless indicated otherwise in a credit line to the material. If material is not included in the article's Creative Commons licence and your intended use is not permitted by statutory regulation or exceeds the permitted use, you will need to obtain permission directly from the copyright holder. To view a copy of this licence, visit http://creativecommons.org/licenses/by/4.0/ The Creative Commons Public Domain Dedication waiver (http://creativecommons.org/publicdomain/zero/1.0/) applies to the data made available in this article, unless otherwise stated in a credit line to the data. 
disabilities to severe malformations with profound intellectual disability $[5,7,8]$. The birth of children with 22q11.2DS or 22q11.2DupS causes extreme emotional and financial burdens on society and the family. However, very few studies have evaluated the performance of prenatal diagnosis and assessment in managing these diseases.

In the present study, we retrospectively analyzed prenatal clinical features and performed single-nucleotide polymorphism chromosome microarray technology (SNP-array analysis)-based diagnostic detection in 411 pregnant women recruited during the past 4 years. These results may be useful for pregnant women and their families regarding the prognosis of the fetus before delivery.

\section{Materials and methods}

\section{Patients}

The present study was carried out according to the principles of the Declaration of Helsinki and approved by Jiaxing Maternity and Child Health Care Hospital Affiliated with Jiaxing University's Ethics Committee. Written informed consent was obtained for all human subjects participating in this case series study. From January 2015 to December 2018, a total of 411 pregnant women were recruited, among whom 275 presented with structural abnormalities in the fetus during ultrasound scanning; the remaining 136 were identified to be at high risk by Down's serological screening and were subsequently confirmed to have chromosomal abnormalities by amniotic fluid karyotype analysis or prenatal BoBs test.

\section{Amniotic fluid karyotype analysis}

Amniotic fluid $(20 \mathrm{~mL})$ was collected by amniocentesis under ultrasonic guidance and then centrifuged at $800 \times \mathrm{g} / \mathrm{min}$ for $10 \mathrm{~min}$. After removing the supernatant, the remaining $1.5 \mathrm{~mL}$ of liquid was mixed and inoculated in two $3.5-\mathrm{mL}$ culture bottles containing AmnioMAX ${ }^{\mathrm{mm}}$ II Complete culture medium (BIOAMF ${ }^{\mathrm{m}}-2$, Biological Industries, Inc.). The culture medium was changed 6-7 days after inoculation. The cells were collected, and sections were prepared for Giemsa banding when more than 10 cell colonies were present. Images were scanned and collected by using a Leica Biosystems GSL-120 and Lecia CytoVisin analysis system (California Richmond, USA). We analyzed 5 mitotic figures and 30 counts for each sample.

\section{Prenatal BACs on BEADS ${ }^{\mathrm{TM}}\left(\mathrm{BoBs}^{\mathrm{TM}}\right)$ technology}

Prenatal BoBs ${ }^{\text {Tx }}$ (Luminex 200, Technology Boulevard Austin, Texas, USA) is a rapid, microsphere-based suspension array technology used to discover common aneuploidies (13, 18, and 21) and nine frequent microdeletion/microduplication syndromes, including
Williams-Beuren, DiGeorge I and II, Prader-Willi, Angelman, Cri du Chat, Smith-Magenis, LangerGiedion, Miller-Dieker and Wolf-Hirschhorn.

DNA was extracted from amniotic fluid cells and detected with Prenatal $\mathrm{BoBs}^{\mathrm{Tn}}$ technology. Positive results were supported by SNP-array analysis.

\section{SNP-array analysis}

High-resolution, genome-wide SNP-array analysis was performed using the Affymetrix CytoScan $750 \mathrm{~K}$ arrays technology platform (Santa Clara, CA, USA) according to the manufacturer's protocols. The results were analyzed with ChAS v3.0 software (Thermo Fisher Scientific, Waltham, MA, USA).

\section{Fluorescence in situ hybridization (FISH)}

Fluorescence in situ hybridization analysis (using the Di George syndrome-specific flanking N25 region probe coupled with an LSI ARSA control probe that maps to the telomeric end of 22q13) was performed according to the manufacturer's instructions (Abbott Laoratories, USA) for at least 30 interphase nuclei. A FISH result for interphase nuclei with three separate red fluorescent signals indicated a duplication event.

\section{Results}

Among the 411 pregnant women who showed either abnormal prenatal ultrasound findings or positive prenatal $\mathrm{BoBs}^{\text {tm }}$ results or who had given birth to a child with chromosomal abnormalities, SNP-array analysis identified five fetuses with 22q11.2 copy number variants (CNVs), three of which were 22q11.2DS and two of which were 22q11.2DupS (Table 1). Except for the P5 fetus with a duplication of $2.8 \mathrm{Mb}$, the copy number variations of the other four fetuses were all approximately 3.1 Mb. The prenatal positive detection rate of $22 \mathrm{q} 11.2$ microdeletion was 7.30 in 1000 fetuses (3/411), and the positive detection rate of $22 \mathrm{q} 11.2$ microduplication was 4.87 in 1000 fetuses (2/411). These figures reflect the incidence of 22q11.2 CNV high-risk populations in China.

G-banded chromosome analysis of prenatal amniotic fluid cells revealed normal karyotypes in all 5 confirmed fetuses (Fig. 1a). Prenatal BoBs ${ }^{\mathrm{sm}}$ technology only indicated an increased signal in two fetuses in the 22q11.2 region (Fig. 1b) but was unable to determine the size and genes contained in the region. The SNP-array analysis technique was able to identify the size of amplification and the genes in this region (Fig. 1c). The three fetuses with 22q11.2DS and ultrasound abnormalities were directly diagnosed by SNP-array analysis (Fig. 1d). Interphase FISH analysis identified one of the 22q11.2 microduplications (P5) by using the Di George syndrome-specific flanking N25/ARSA probe (Fig. 1e). In all 5 fetuses with the diagnosed 22q11.2 
Table 1 Pregnancy details and clinical features of the patients

\begin{tabular}{|c|c|c|c|c|c|c|c|c|c|c|c|}
\hline Patient & Age & $\mathrm{G} / \mathrm{P} / \mathrm{A} / \mathrm{L}$ & $\begin{array}{l}\text { Gestational } \\
\text { week }\end{array}$ & T21 & T18 & NTD Risk & $\mathrm{NT}(\mathrm{mm})$ & Syndrome & CNVs Size & Clinical indication & Outcome \\
\hline P1 & 25 & $0-0-0-0$ & 23 & $1 / 2300$ & $1 / 36400$ & Negative & $0.9 \mathrm{~mm}$ & $22 q 11.2 D S$ & $3.1 \mathrm{Mb}$ & $\begin{array}{l}\text { Fetal heart malformation, } \\
\text { separation of left kidney } \\
\text { collecting system }\end{array}$ & $\begin{array}{l}\text { Termination } \\
\text { of pregnancy }\end{array}$ \\
\hline P2 & 25 & $0-0-0-0$ & 23 & $1 / 6824$ & $1 / 100000$ & Negative & $5.8 \mathrm{~mm}$ & $22 q 11.2 D S$ & $3.1 \mathrm{Mb}$ & Fetal neck water cyst & $\begin{array}{l}\text { Termination } \\
\text { of pregnancy }\end{array}$ \\
\hline P3 & 30 & $1-0-0-1$ & 22 & $1 / 3777$ & $1 / 100000$ & Negative & Not done & $22 \mathrm{q} 11.2 \mathrm{DS}$ & $3.1 \mathrm{Mb}$ & $\begin{array}{l}\text { Fetal ventricular septal } \\
\text { defect slight tricuspid } \\
\text { regurgitation }\end{array}$ & $\begin{array}{l}\text { Continue } \\
\text { pregnancy }\end{array}$ \\
\hline P4 & 30 & $1-0-0-1$ & 21 & $1 / 53$ & $1 / 22509$ & Negative & $1.2 \mathrm{~mm}$ & 22q11.2Dups & $3.1 \mathrm{Mb}$ & $\begin{array}{l}\text { BoBs result:22q11.2 region } \\
\text { duplication }\end{array}$ & $\begin{array}{l}\text { A } 2 \text { years old } \\
\text { healthy child }\end{array}$ \\
\hline P5 & 31 & $0-0-0-0$ & 22 & $1 / 20$ & $1 / 25507$ & Negative & $1.7 \mathrm{~mm}$ & 22q11.2Dups & $2.8 \mathrm{Mb}$ & $\begin{array}{l}\text { BoBs result:22q11.2 region } \\
\text { duplication }\end{array}$ & $\begin{array}{l}\text { Termination } \\
\text { of pregnancy }\end{array}$ \\
\hline
\end{tabular}

abnormalities, inheritance could not be identified because the parents did not undergo further testing.

Prenatal fetal ultrasound scanning of P1 at 23 weeks gestational age showed tetralogy of Fallot (Fig. 2a) and left kidney collection system separation (Fig. 2b). The double top diameter, head circumference, abdominal circumference, and femur length were all within the normal range, and the spine continuity was complete. Prenatal ultrasound of the P2 fetus suggested a water cyst in the neck (Fig. 2c), and other growth indications were within the normal range. The parents of P1 and P2 chose to terminate the pregnancy. P5 at 22 weeks
A

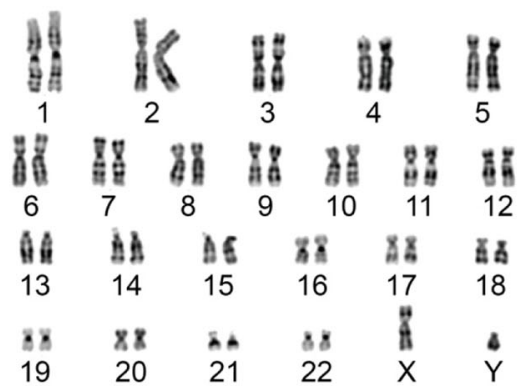

C

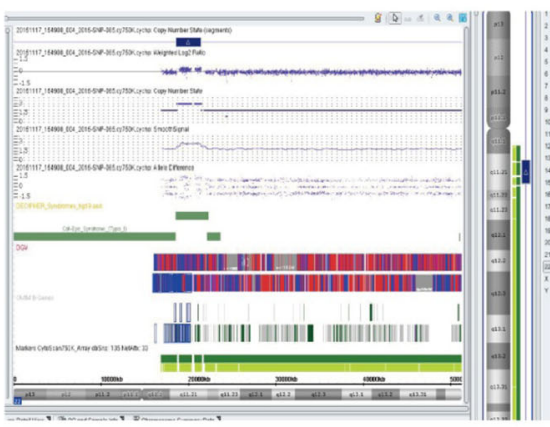

$\mathrm{E}$

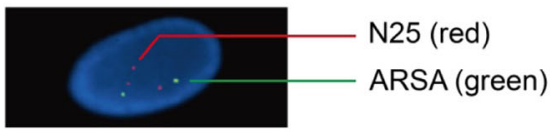

B

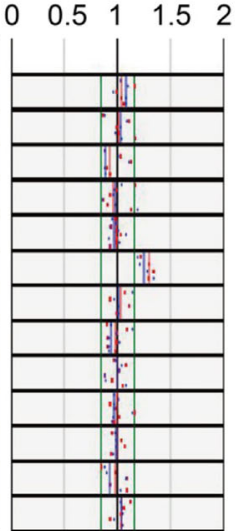

D

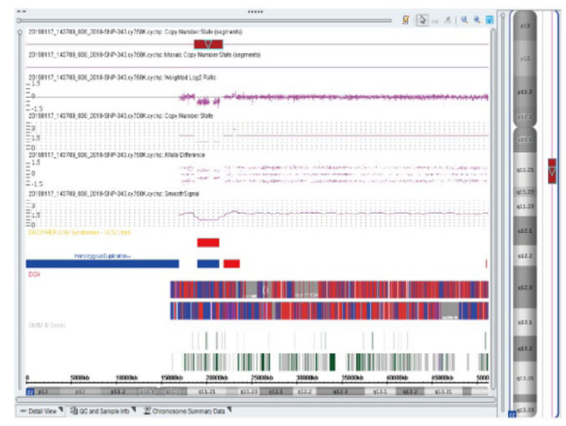

Fig. 1 Karyotype analysis, BoBs ${ }^{\mathrm{TM}}$ analysis, SNP-array analysis, and FISH analysis. a Karyotype of P3, normal karyotype. b BoBs $s^{\mathrm{TM}}$ analysis of P5. The arrow indicates DiGeorge syndrome region amplification. c SNP-array analysis of P5. The thick blue line indicates duplication of the $22 \mathrm{q} 11.2$ region. $\mathbf{d}$ SNP-array analysis of P3. The thick red line indicates deletion of the 22q11.2 region. e FISH analysis of P5. N25 (red) indicates duplication of the DiGeorge region 


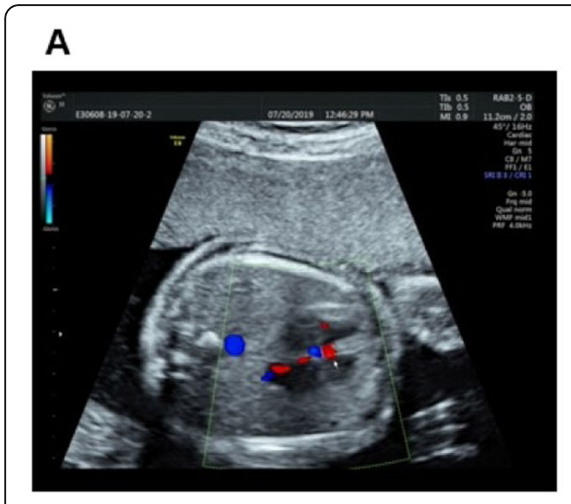

D

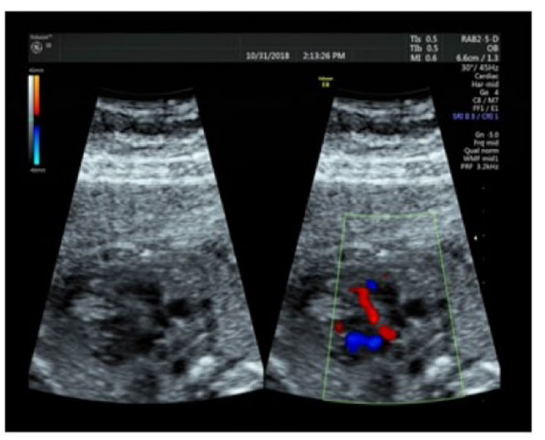

B

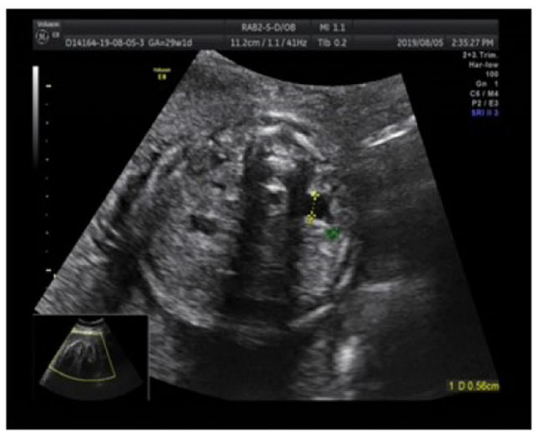

E

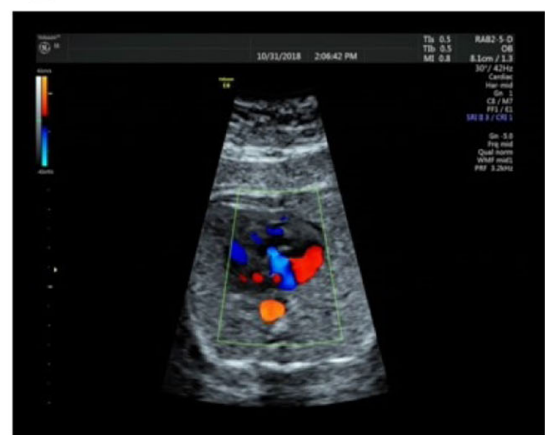

Fig. 2 Prenatal ultrasonographic findings of the fetus. a P1 fetus at 23 weeks gestational age, showing ultrasonographic findings of tetralogy of Fallot. b P1 fetus, showing ultrasonographic findings of left kidney collection system separation. c P2 fetus, showing ultrasonographic findings of a water cyst in the neck. d P3 fetus, showing ultrasonic findings of tricuspid regurgitation. e P3 fetus, showing a perimembranous ventricular septal defect

gestational age did not reveal any abnormal prenatal ultrasound findings. However, the parents chose to terminate the pregnancy because of fear of abnormalities in the neurologic development after birth after receiving the genetic diagnosis of 22q11.2DupS.

Echocardiography of the P3 fetus revealed a $0.28 \mathrm{~cm}$ perimembranous ventricular septal defect (Fig. 2d) and tricuspid regurgitation (Fig. 2e). The ascending aorta was slightly distorted; other growth indicators were within the normal range. After genetic counseling, the pregnant woman and her husband choose to continue the pregnancy, and the baby had not yet been delivered at the time of writing. Prenatal ultrasound of the P4 fetus did not reveal any anomalies, so the pregnant woman chose to continue the pregnancy and have a normal birth. The child is now a 2-year-old girl, and physical and mental examinations did not reveal any abnormalities (height $86 \mathrm{~cm}$, weight $12 \mathrm{~kg}$, head circumference $48 \mathrm{~cm}$, heart and lung without murmur, liver and spleen without swelling, no skeletal abnormalities, normal speech and behavior development).

\section{Discussion}

22q11.2DS, otherwise known as DiGeorge syndrome or velo-cardio-facial syndrome, is a well-described genetic syndrome with clinical presentations including congenital heart defects and other malformations. Previous studies did not detect the 22q11.2 deletion in controls, confirming the pathogenic nature of this $\mathrm{CNV}[9,10]$. However, 22q11.2DS syndrome is an underdiagnosed disease in the general population, especially in developing countries. In China, patients with conotruncal defects or 22q11.2DSspecific facial features are underrecognized because it is difficult to recognize the disease solely based on clinical features without knowing the molecular diagnosis $[11,12]$. In our three cases of 22q11.2DS, two fetuses had congenital heart malformations and one had a water cyst on prenatal ultrasound findings. This indicates that fetuses with such ultrasound abnormalities may undergo karyotype analysis and SNP-array analysis to confirm genetic diagnosis.

In the present study, we retrospectively analyzed the clinical features of fetuses with 22q11.2DS and 22q11.2DupS analyzed over the past 4 years by SNParray analysis to provide a clinical basis for prenatal diagnosis of these two common syndromes. Despite the small number of cases, this is the first time that Chinese data for the diagnosis of 22q11.2 CNV by the SNP-array technique have been obtained by amniocentesis. Our detection rate of $22 \mathrm{q} 11.2 \mathrm{DS}(1: 137)$ is similar to that 
reported by Kaminsky et al. (1/169), but 22q11.2DupS shows a lower detection rate (1:205.5), probably because of its milder phenotype [9, 13]. However, the overall positive detection rates in our center for the two syndromes are significantly higher than those reported previously $[1,3,8]$, probably due to our patient selection criteria. The diagnosis would be more convincing if we could obtain the $\mathrm{CNV}$ data of the 5 couples with 22q11.2 region-problem pregnancy. However, such information was not available due to refusal of further inspections from the parents at the time of publication.

Prenatal $\mathrm{BoBs}^{\mathrm{Tat}}$ and SNP-array analysis have become popular diagnostic technologies for common aneuploidies and other microdeletion or microduplication syndromes in the past several years in China [14]. Prenatal $\mathrm{BoBs}^{\mathrm{Tm}}$ is a bead-based multiplex technology that detects chromosome 13,18, 21, and X/Y aneuploidies and nine frequent microdeletion syndromes $[15,16]$. However, whole-genome SNP-array analysis has demonstrated higher resolution and more accurate $\mathrm{CNV}$ detection than $\mathrm{BoBs}^{\mathrm{Tx}}$ technology [9]. In addition, SNP-array analysis can detect many other pathogenic/likely pathogenic microdeletions/duplications in addition to aneuploidy/partial aneuploidy, triploidy, UPD, and other disorders [17]. FISH detection had been the gold standard for identifying microdeletions and microduplications. However, owing to the rapid development of new technologies, it is currently used as a verification method for known variations. Traditional karyotype analysis cannot distinguish copy number variations $<5 \mathrm{Mb}$. Although FISH detection is accurate, it may miss a small fragment or an atypical variation. BoB detection can only provide an indication of the amplification or deletion of the probe signal position. SNP-array technology accurately detects the position, size and genetic content of copy number variations. Therefore, SNP-array technology shows a unique advantage in detecting unknown copy number variations, including 22q11.2 CNVs.

22q11.2DupS is associated with highly variable clinical features, ranging from completely normal to slightly abnormal features with milder learning disabilities to severe intellectual disability $[5,18]$. Therefore, very few cases have been reported, and the absence of obvious clinical features makes diagnosis difficult [19]. Similarly, no ultrasound abnormalities were observed in the two cases of 22q11.2DupS in this study. The parents of one fetus chose to give birth to the child; the child is now 2 years old and healthy. The other pregnant woman chose to terminate the pregnancy because of concerns regarding their child's potential postnatal mental problems. These results and those from the literature [8] suggest that 22q11.2DupS does not have an accurate clinical phenotype. The extent of correlation between the phenotype and $\mathrm{CNV}$ depends on many factors, including previous evidence of pathogenic CNVs in the same region, type of $\mathrm{CNV}$ (duplication or deletion), gene content, inheritance pattern, and frequency in healthy populations $[9,19]$. Our case reports have provided useful information for subsequent research and genetic counseling. The collection of clinical data from largerscale studies of 22q11.2DupS is necessary for this type of analysis to provide evidence for prenatal diagnosis and genetic counseling.

\section{Conclusion}

Our case reports provide a detection rate of 22q11.2 $\mathrm{CNVs}$ for fetuses with prenatal diagnosis indications and further indicate that SNP-array technology is an effective tool in the prenatal diagnosis of 22q11.2 CNVs. The prenatal diagnosis of these two syndromes is helpful for early intervention, which is of great clinical significance.

\section{Acknowledgments}

The authors most honestly appreciate the patients for their participation in this study and all colleagues in the Department of Prenatal Diagnosis and Pediatric Surgery of the Maternity and Child Health Care Hospital Affiliated with Jiaxing University for their assistance in the present study and Dr. Qingquan Zhang (BGl Genomics, BGI-Shenzhen, Shenzhen 518083, China) for assistance in editing the text.

We also thank Dr. Jiong Gao (BGl Genomics, BGI-Shenzhen, Shenzhen

518083, China) and Dr. Hongjun Shi (Westlake University, Hangzhou 310024,

China) for their assistance during the writing of this manuscript.

\section{Authors' contributions}

$\mathrm{SL}, \mathrm{YJ}$ and PT carried out the assays and participated in designing the study. JY, HS and JD carried out clinical consultations. CZ, LW and LY carried out laboratory tests and prepared the Figs. SL, JC and HS conceived the study, participated in its design and coordination, and wrote the manuscript. All authors read and approved the final manuscript.

\section{Funding}

This study was supported by the grants from the Public Welfare Technology Research Program of Zhejiang Province (LGF19H040005 and LGF18H040008), Health Development Planning Commission of Zhejiang Province (2019KY221 and 2017KY654), Technology Bureau of Jiaxing, Zhejiang Province (2018AY32022), Research Fund for Academician Lin He New Medicine (19331201 and 19331202).

\section{Availability of data and materials}

The data used or analyzed during the current study are avaible from the corresonding author on reasonable request.

Ethics approval and consent to participate

All patient-related data were collected retrospectively and anonymously. Thestudy was approved by Jiaxing Maternity and Child Health Care Hospital Affiliated to Jiaxing University's Ethics Committee.

\section{Consent for publication}

Not applicable.

\section{Competing interests}

The authors have no conflicts of interest relevant to this article.

Received: 11 February 2020 Accepted: 24 June 2020

Published online: 08 July 2020

\section{References}

1. Wenger TL, Miller JS, DePolo LM, de Marchena AB, Clements CC, Emanuel BS, Zackai EH, McDonald-McGinn DM, Schultz RT. 22q11.2 duplication syndrome: elevated rate of autism spectrum disorder and need for medical screening. Mol Autism. 2016;7:27. 
2. McDonald-McGinn DM, Sullivan KE, Marino B, Philip N, Swillen A, Vorstman JA, Zackai EH, Emanuel BS, Vermeesch JR, Morrow BE, et al. 22q11.2 deletion syndrome. Nat Rev Dis Primers. 2015;1:15071.

3. Vingerhoets $C$, van Oudenaren MJF, Bloemen OJN, Boot E, van Duin EDA, Evers LJM, Fiksinski AM, Breetvelt EJ, Palmer LD, Vergaelen E, et al. Low prevalence of substance use in people with 22q11.2 deletion syndrome[J]. Br J Psychiatry. 2019;215(5):661-7.

4. Shaikh TH, O'Connor RJ, Pierpont ME, McGrath J, Hacker AM, Nimmakayalu M, Geiger E, Emanuel BS, Saitta SC. Low copy repeats mediate distal chromosome 22q11.2 deletions: sequence analysis predicts breakpoint mechanisms. Genome Res. 2007;17(4):482-91.

5. Ou Z, Berg JS, Yonath H, Enciso VB, Miller DT, Picker J, Lenzi T, Keegan CE, Sutton VR, Belmont J, et al. Microduplications of 22q11.2 are frequently inherited and are associated with variable phenotypes. Genet Med. 2008; 10(4):267-77.

6. Turner DJ, Miretti M, Rajan D, Fiegler H, Carter NP, Blayney ML, Beck S, Hurles ME. Germline rates of de novo meiotic deletions and duplications causing several genomic disorders. Nat Genet. 2008;40(1):90-5.

7. Portnoi MF. Microduplication 22q11.2: a new chromosomal syndrome. Eur J Med Genet. 2009:52(2-3):88-93.

8. Dupont C, Grati FR, Choy KW, Jaillard S, Toutain J, Maurin ML, MartinezConejero JA, Beneteau C, Coussement A, Molina-Gomes D, et al. Prenatal diagnosis of 24 cases of microduplication 22q11.2: an investigation of phenotype-genotype correlations. Prenat Diagn. 2015;35(1):35-43.

9. Kaminsky EB, Kaul V, Paschall J, Church DM, Bunke B, Kunig D, Moreno-DeLuca D, Moreno-De-Luca A, Mulle JG, Warren ST, et al. An evidence-based approach to establish the functional and clinical significance of copy number variants in intellectual and developmental disabilities. Genet Med. 2011;13(9):777-84

10. Bassett AS, Lowther C, Merico D, Costain G, Chow EWC, van Amelsvoort T, McDonald-McGinn D, Gur RE, Swillen A, Van den Bree M, et al. Rare genome-wide copy number variation and expression of schizophrenia in 22q11.2 deletion syndrome. Am J Psychiatry. 2017;174(11):1054-63.

11. Liu APY, Chow P-C, Lee PPW, Mok GTK, Tang W-F, Lau ET, Lam STS, Chan KY, Kan ASY, Chau AKT, et al. Under-recognition of 22q11.2 deletion in adult Chinese patients with conotruncal anomalies: implications in transitional care. Eur J Med Genet. 2014;57(6):306-11.

12. Dermaut B, Wu D, Chen Y, Xu C, Wang K, Wang H, Zheng F, Ma D, Wang G. Characteristic Face: A Key Indicator for Direct Diagnosis of 22a11.2 Deletions in Chinese Velocardiofacial Syndrome Patients. PLoS One. 2013; 8(1):e54404.

13. Koczkowska M, Wierzba J, Smigiel R, Sasiadek M, Cabala M, Slezak R, lliszko M, Kardas I, Limon J, Lipska-Zietkiewicz BS. Genomic findings in patients with clinical suspicion of 22q11.2 deletion syndrome. J Appl Genet. 2017; 58(1):93-8.

14. Shaffer LG, Coppinger J, Morton SA, Alliman S, Burleson J, Traylor R, Walker C, Byerly S, Lamb AN, Schultz R, et al. The development of a rapid assay for prenatal testing of common aneuploidies and microdeletion syndromes. Prenat Diagn. 2011;31(8):778-87.

15. Vialard F, Simoni G, Gomes DM, Abourra A, De Toffol S, Bru F, Martinez Romero MC, Nitsch L, Bouhanna P, Marcato L, et al. Prenatal BACs-on-beads: the prospective experience of five prenatal diagnosis laboratories. Prenat Diagn. 2012;32(4):329-35.

16. Xiao H, Yang YL, Zhang CY, Liao EJ, Zhao HR, Liao SX. Karyotype analysis with amniotic fluid in 12365 pregnant women with indications for genetic amniocentesis and strategies of prenatal diagnosis. J Obstet Gynaecol. 2016; 36(3):293-6.

17. Halder A, Jain M, Kalsi AK. SNP Microarray in FISH Negative Clinically Suspected 22q11.2 Microdeletion Syndrome. Scientifica (Cairo). 2016;2016: 5826431.

18. Cooper GM, Coe BP, Girirajan S, Rosenfeld JA, Vu TH, Baker C, Williams C, Stalker H, Hamid R, Hannig V, et al. A copy number variation morbidity map of developmental delay. Nat Genet. 2011;43(9):838-46.

19. Kylat Rl. 22q11.2 microduplication: an enigmatic genetic disorder. J Pediatr Genet. 2018;7(3):138-42.

\section{Publisher's Note}

Springer Nature remains neutral with regard to jurisdictional claims in published maps and institutional affiliations.

Ready to submit your research? Choose BMC and benefit from:

- fast, convenient online submission

- thorough peer review by experienced researchers in your field

- rapid publication on acceptance

- support for research data, including large and complex data types

- gold Open Access which fosters wider collaboration and increased citations

- maximum visibility for your research: over $100 \mathrm{M}$ website views per year

At $\mathrm{BMC}$, research is always in progress.

Learn more biomedcentral.com/submissions 